ARTICLE

https://doi.org/10.1038/s41467-020-18119-y

\title{
Highly efficient eco-friendly X-ray scintillators based on an organic manganese halide
}

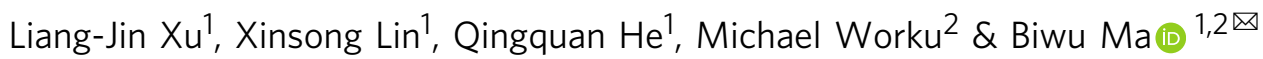

Scintillation based $\mathrm{X}$-ray detection has received great attention for its application in a wide range of areas from security to healthcare. Here, we report highly efficient $X$-ray scintillators with stateof-the-art performance based on an organic metal halide, ethylenebis-triphenylphosphonium manganese (II) bromide $\left(\left(\mathrm{C}_{38} \mathrm{H}_{34} \mathrm{P}_{2}\right) \mathrm{MnBr}_{4}\right)$, which can be prepared using a facile solution growth method at room temperature to form inch sized single crystals. This zero-dimensional organic metal halide hybrid exhibits green emission peaked at $517 \mathrm{~nm}$ with a photoluminescence quantum efficiency of $\sim 95 \%$. Its $X$-ray scintillation properties are characterized with an excellent linear response to $\mathrm{X}$-ray dose rate, a high light yield of $\sim 80,000$ photon $\mathrm{MeV}^{-1}$, and a low detection limit of $72.8 \mathrm{nGy} \mathrm{s} \mathrm{s}^{-1}$. X-ray imaging tests show that scintillators based on $\left(\mathrm{C}_{38} \mathrm{H}_{34} \mathrm{P}_{2}\right) \mathrm{MnBr}_{4}$ powders provide an excellent visualization tool for $\mathrm{X}$-ray radiography, and high resolution flexible scintillators can be fabricated by blending $\left(\mathrm{C}_{38} \mathrm{H}_{34} \mathrm{P}_{2}\right) \mathrm{MnBr}_{4}$ powders with polydimethylsiloxane.

\footnotetext{
${ }^{1}$ Department of Chemistry and Biochemistry, Florida State University, Tallahassee, FL 32306, USA. ${ }^{2}$ Materials Science and Engineering Program, Florida State University, Tallahassee, FL 32306, USA. ${ }_{\text {email: bma@fsu.edu }}$
} 
S cintillators, with the ability to convert ionizing radiation into visible photons, have received extensive attention in recent years, as they can be used as radiation detectors for radiation exposure monitoring, security inspection, space exploration, and medical imaging ${ }^{1-4}$. While various types of materials have been used for X-ray scintillators, there are still many issues and limitations to existing organic and inorganic scintillation materials, for example, rigorous conditions required for the preparation of inorganic crystals and their hygroscopicity, anisotropic scintillation of organic crystals, low light yields in plastics, and so on ${ }^{5-9}$. Therefore, searching for low-cost, highperformance scintillation materials is still of great scientific and practical interest.

Recently, lead halide perovskites, such as $\mathrm{CsPbBr}_{3}$ and $\mathrm{MAPbBr}_{3}$, have been demonstrated in direct X-ray imaging, owing to their strong $\mathrm{X}$-ray absorption and efficient conversion to charge carriers $^{10-20}$. X-ray scintillators have also been developed using highly emissive metal halide perovskite nanocrystals ${ }^{21-26}$. However, the toxicity of lead in these halide perovskites might limit their potential commercial applications. In this regard, lead-free metal halide perovskites and hybrids with efficient charge extraction and high photoluminescence quantum efficiencies (PLQEs) for X-ray detectors have received increasing interests ${ }^{27-33}$. For instance, Tang's group reported sensitive X-ray detectors using double perovskite $\mathrm{Cs}_{2} \mathrm{AgBiBr}_{6}$ single crystals ${ }^{31}$. More recently, the use of low-dimensional metal hybrids, such as $\mathrm{Bmpip}_{2} \mathrm{SnBr}_{4}$ and $\mathrm{Rb}_{2} \mathrm{CuX}_{3}(\mathrm{X}=\mathrm{Cl}$ and $\mathrm{Br})$, for scintillators has been demonstrated by Kovalenko's and Tang's groups, respectively ${ }^{32-34}$.

Eco-friendly organic manganese (II) halide hybrids have been reported to exhibit strong photoluminescence (PL) with colors ranging from green to red $^{35-40}$. The luminescence mechanisms of this class of materials are well known, that is, from the $\mathrm{d}-\mathrm{d}$ transitions in tetrahedral and octahedral crystal fields for green and red emissions, respectively 37,41 . For their excellent optical properties, various applications have been demonstrated using organic manganese (II) halide hybrids. For instance, organic light-emitting diodes with external quantum efficiencies of $\sim 10 \%$ have been reported by using tetrabromide manganese (II) complex $\left(\mathrm{PPh}_{4}\right)_{2} \mathrm{MnBr}_{4}{ }^{35}$ and dibenzofuran-based phosphine oxide manganese (II) bromides (DBFDPO- $\left.\mathrm{MnBr}_{2}\right)^{42}$. Luminescent vapochromism has also been realized via the reversible conversion of ligand fields in diphenylphosphine oxide-based manganese (II) hybrids $\mathrm{MnBr}_{2}\left(\mathrm{dppeO}_{2}\right)^{38}$. A selective fluorescent sensor for different organic solvents was recently demonstrated using $\left(\mathrm{C}_{9} \mathrm{NH}_{20}\right)_{2} \mathrm{MnBr}_{4}{ }^{36}$. To the best of our knowledge, the attempt on scintillators based on organic manganese (II) halide hybrids has not been reported yet.

Here, we demonstrate high-performance eco-friendly X-ray scintillators based on a $0 \mathrm{D}$ phosphonium manganese (II) bromide hybrid $\left(\mathrm{C}_{38} \mathrm{H}_{34} \mathrm{P}_{2}\right) \mathrm{MnBr}_{4}$. This organic manganese (II) halide hybrid can be easily prepared by using low-cost commercially available raw materials via a facile room-temperature solvent diffusion method with excellent repeatability and large scalability. High-quality $\left(\mathrm{C}_{38} \mathrm{H}_{34} \mathrm{P}_{2}\right) \mathrm{MnBr}_{4}$ single crystals with sizes of $>1$ in. show great thermal stability and bright green emission peaked at $517 \mathrm{~nm}$ with a PLQE of $\sim 95 \%$. Scintillators based on $\left(\mathrm{C}_{38} \mathrm{H}_{34} \mathrm{P}_{2}\right)$ $\mathrm{MnBr}_{4}$ display great performance with exceptional linearity, high light yield, and low detection limits, which enable high-resolution $\mathrm{X}$-ray images.

\section{Results}

Synthesis and characterization. Similar to other low-dimensional organic metal halide hybrids reported by our group ${ }^{28-30}, 0 \mathrm{D}$ $\left(\mathrm{C}_{38} \mathrm{H}_{34} \mathrm{P}_{2}\right) \mathrm{MnBr}_{4}$ single crystals were obtained by diffusing diethyl ether into a dichloromethane (DCM) precursor solution containing ethylenebis(triphenylphosphonium bromide) $\left(\mathrm{C}_{38} \mathrm{H}_{34} \mathrm{P}_{2} \mathrm{Br}_{2}\right)$ and $\mathrm{MnBr}_{2}$ in a ratio of 1:1. The details of synthesis and purification could be found in Supplementary Scheme 1 and Fig. 1. The crystal structure of $\left(\mathrm{C}_{38} \mathrm{H}_{34} \mathrm{P}_{2}\right) \mathrm{MnBr}_{4}$ single crystals was determined by single-crystal X-ray diffraction (SCXRD). As shown in Fig. 1a and Supplementary Fig. 2, $\left(\mathrm{C}_{38} \mathrm{H}_{34} \mathrm{P}_{2}\right) \mathrm{MnBr}_{4}$ crystallizes at a monoclinic space group of $\mathrm{C}_{2 / c}$, possessing $0 \mathrm{D}$ structure at the molecular level with $\mathrm{MnBr}_{4}$ tetrahedrons isolated and surrounded by $\mathrm{C}_{38} \mathrm{H}_{34} \mathrm{P}_{2}{ }^{2+}$ cations. The manganese center adopts a typical tetra-coordinated geometry bonded to bromide ions, with an average $\mathrm{Mn}-\mathrm{Br}$ bond length of $2.51 \AA$ and bond angle of $108.48^{\circ}$ (Supplementary Tables 1 and 2), similar to those of previously reported $\mathrm{MnBr}_{4}$ complexes ${ }^{35}$. The powder XRD pattern of $\left(\mathrm{C}_{38} \mathrm{H}_{34} \mathrm{P}_{2}\right) \mathrm{MnBr}_{4}$ powder is identical to the simulated result from SCXRD data (Fig. 1b), suggesting the high phase purity of the as-prepared single crystals. No weight loss was observed before $310^{\circ} \mathrm{C}$ in thermogravimetric analysis (TGA) as shown in Supplementary Fig. 3, suggesting a high thermal stability. The differential scanning calorimetry (DSC) results with an endothermic peak at $295^{\circ} \mathrm{C}$ (Supplementary Fig. 3), which could be the melting point of $\left(\mathrm{C}_{38} \mathrm{H}_{34} \mathrm{P}_{2}\right) \mathrm{MnBr}_{4}$, suggest its high phase stability at elevated temperatures below $295^{\circ} \mathrm{C}$.

Photophysical properties. The $\left(\mathrm{C}_{38} \mathrm{H}_{34} \mathrm{P}_{2}\right) \mathrm{MnBr}_{4}$ single crystals are pale green under ambient light and become highly emissive upon irradiating with ultraviolet (UV) light as shown in Fig. 1c, d. The photophysical properties were further investigated using UV-vis absorption and steady-state PL spectroscopies. As shown in Fig. 1e, $\left(\mathrm{C}_{38} \mathrm{H}_{34} \mathrm{P}_{2}\right) \mathrm{MnBr}_{4}$ exhibits an intense absorption band around $285 \mathrm{~nm}$ along with two absorption peaks at 360 and $450 \mathrm{~nm}$. The excitation spectrum has the same features as the absorption spectrum in a low-energy band, which are corresponding to two groups of transitions: ${ }^{6} \mathrm{~A}_{1} \rightarrow{ }^{4} \mathrm{G}$ and ${ }^{6} \mathrm{~A}_{1} \rightarrow{ }^{4} \mathrm{D}$. (See the optical transitions in tetrahedrally coordinated $\mathrm{Mn}^{2+}$ ion in Supplementary Scheme 2.) Upon irradiation in the range of 300-400 nm, bright green emission peaked at $517 \mathrm{~nm}$ was observed with a full-width at half-maximum of $51 \mathrm{~nm}$, a high PLQE of $\sim 95 \%$, and a long single-exponential decay lifetime of $318 \mu$ s $\left(R^{2}=0.999\right)$ (Supplementary Fig. 4). The strong green emission is well known to be from $\mathrm{d}-\mathrm{d}^{4} \mathrm{~T}_{1} \rightarrow{ }^{6} \mathrm{~A}_{1}$ transition of $\mathrm{Mn}^{2+}$ ion with a tetrahedral coordination geometry. Moreover, $\left(\mathrm{C}_{38} \mathrm{H}_{34} \mathrm{P}_{2}\right) \mathrm{MnBr}_{4}$ demonstrated great moisture stability with PL intensity unchanged after exposure in an ambient atmosphere for 1 month (Supplementary Fig. 5). The high emission efficiency together with good quality of facilely prepared single crystals suggest the suitability of $\left(\mathrm{C}_{38} \mathrm{H}_{34} \mathrm{P}_{2}\right) \mathrm{MnBr}_{4}$ for luminescent devices.

$\mathrm{X}$-ray scintillation properties. To explore the scintillation performance of $\left(\mathrm{C}_{38} \mathrm{H}_{34} \mathrm{P}_{2}\right) \mathrm{MnBr}_{4}$, a commercially available scintillation material, cerium-doped lutetium aluminum garnet (Ce: LuAG), was used as a standard reference as it exhibits a similar $\mathrm{PL}$ emission peaked at $\sim 520 \mathrm{~nm}$ that could minimize the influence of response difference by detectors. The $\mathrm{X}$-ray radioluminescence (RL) spectra of $\left(\mathrm{C}_{38} \mathrm{H}_{34} \mathrm{P}_{2}\right) \mathrm{MnBr}_{4}$ and Ce:LuAG were obtained by using Edinburgh FS5 fluorescence spectrophotometer equipped with a X-ray generator (Amptek Mini-X tube, Au target, $4 \mathrm{~W}$ ). As shown in Supplementary Fig. 6, both RL emissions are identical to their PL emissions. Interestingly, the RL intensity of $\left(\mathrm{C}_{38} \mathrm{H}_{34} \mathrm{P}_{2}\right) \mathrm{MnBr}_{4}$ is $>3$ times higher than that of Ce: LuAG under the same $\mathrm{X}$-ray dose rate irradiation. Moreover, the $\mathrm{X}$-ray image of $\left(\mathrm{C}_{38} \mathrm{H}_{34} \mathrm{P}_{2}\right) \mathrm{MnBr}_{4}$ single crystals is much brighter than that of Ce:LuAG, as shown in Fig. 2a, suggesting that $\left(\mathrm{C}_{38} \mathrm{H}_{34} \mathrm{P}_{2}\right) \mathrm{MnBr}_{4}$ is more sensitive to $\mathrm{X}$-ray irradiation than Ce: LuAG. To evaluate the scintillator response to $\mathrm{X}$-ray dose rate, the $\mathrm{RL}$ intensities were measured under various X-ray dose rates for 

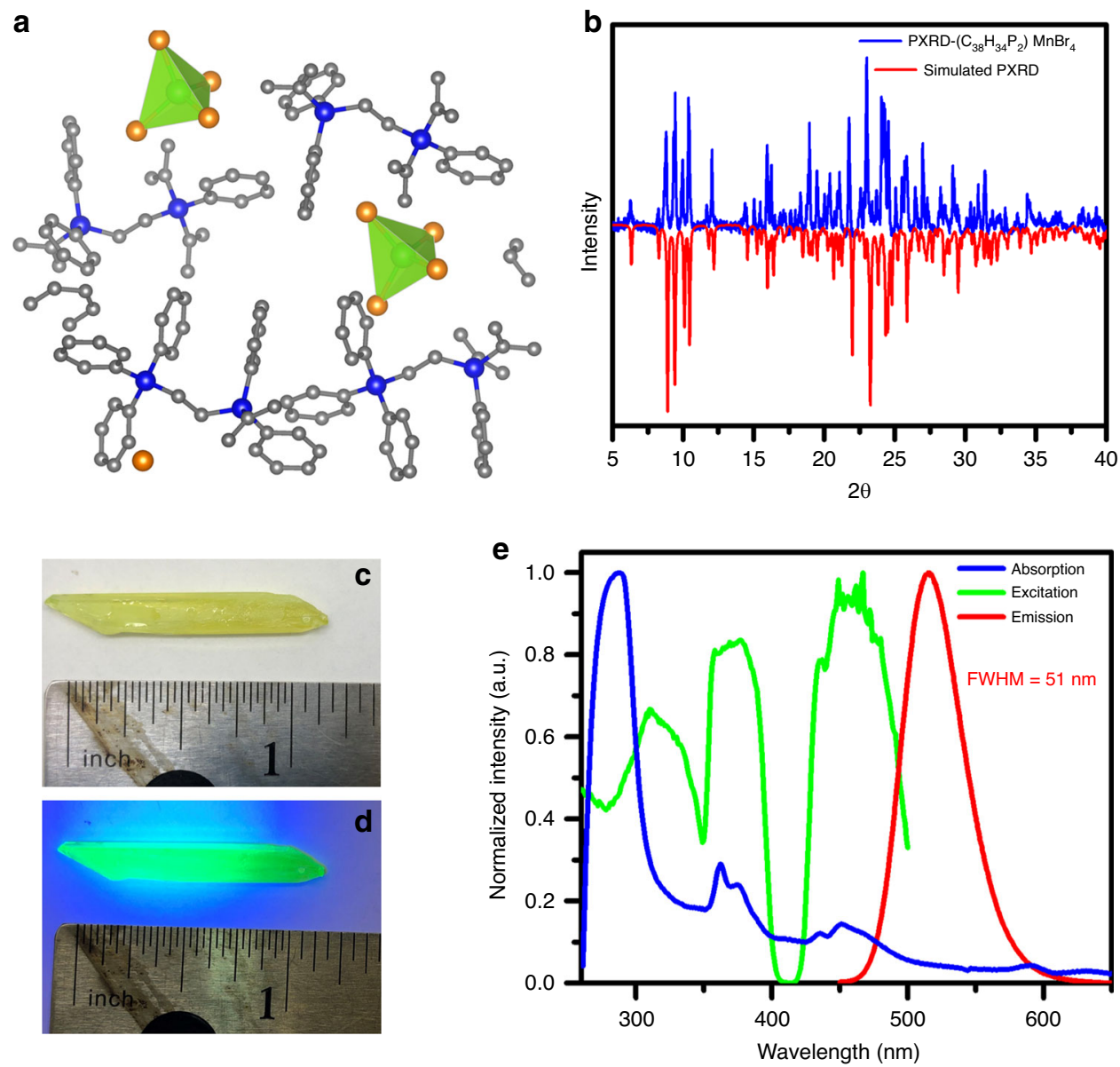

Fig. 1 Structural and photophysical characterization of $\left(\mathbf{C}_{\mathbf{3 8}} \mathbf{H}_{\mathbf{3} 4} \mathbf{P}_{\mathbf{2}}\right) \mathbf{M n B r}_{\mathbf{4}}$ single crystals. a View of the single-crystal structure of $\left(\mathrm{C}_{38} \mathrm{H}_{34} \mathrm{P}_{2}\right) \mathrm{MnBr}_{4}(\mathrm{Mn}$ green, $\mathrm{Br}$ orange, $\mathrm{P}$ blue, $\mathrm{C}$ gray; hydrogen atoms were hidden for clarity). $\mathbf{b}$ PXRD patterns of $\left(\mathrm{C}_{38} \mathrm{H}_{34} \mathrm{P}_{2}\right) \mathrm{MnBr}_{4}$ and the corresponding simulated peaks from the single-crystal structure. The images of a $\left(\mathrm{C}_{38} \mathrm{H}_{34} \mathrm{P}_{2}\right) \mathrm{MnBr}_{4}$ single crystal under daylight (c) and UV light (d). e Absorption, excitation, and emission spectra of $\left(\mathrm{C}_{38} \mathrm{H}_{34} \mathrm{P}_{2}\right) \mathrm{MnBr}_{4}$.

$\left(\mathrm{C}_{38} \mathrm{H}_{34} \mathrm{P}_{2}\right) \mathrm{MnBr}_{4}$ and Ce:LuAG. Figure $2 \mathrm{~b}$ and Supplementary Fig. 7 show that both scintillators exhibit excellent linearities to the X-ray dose rates in a large range from $36.7 \mathrm{nGy} \mathrm{s}^{-1}$ to $89.4 \mu \mathrm{Gy} \mathrm{s}^{-1}$. Moreover, $\left(\mathrm{C}_{38} \mathrm{H}_{34} \mathrm{P}_{2}\right) \mathrm{MnBr}_{4}$ exhibits a higher response to X-ray dose than Ce:LuAG with a larger slope. The reproducibility of the responses to X-ray for $\left(\mathrm{C}_{38} \mathrm{H}_{34} \mathrm{P}_{2}\right) \mathrm{MnBr}_{4}$ was validated by using single crystals with different sizes and shapes. Almost the same sensitivity was recorded for all the samples, as shown in Supplementary Fig. 8. The detection limit of $\mathrm{X}$-ray dose rate was derived to be $72.8 \mathrm{nGy} \mathrm{s}^{-1}$ for $\left(\mathrm{C}_{38} \mathrm{H}_{34} \mathrm{P}_{2}\right)$ $\mathrm{MnBr}_{4}$ when the signal-to-noise ratio (SNR) is 3 , which is $\sim 75$ times lower than the dose rate required for X-ray diagnostics $\left(5.5 \mu \mathrm{Gy} \mathrm{s}^{-1}\right)^{12}$. Light yield is another important parameter to evaluate the performance of scintillators, which is dependent on the amplitude of X-ray response and the RL spectra. Since the Xray dose response of $\left(\mathrm{C}_{38} \mathrm{H}_{34} \mathrm{P}_{2}\right) \mathrm{MnBr}_{4}$ is 3.2 times higher than that of Ce:LuAG (with a light yield of 25,000 photon $\mathrm{MeV}^{-1}$ ) and they have a similar RL spectrum, the light yield of $\left(\mathrm{C}_{38} \mathrm{H}_{34} \mathrm{P}_{2}\right)$ $\mathrm{MnBr}_{4}$ could be derived to be $\sim 79,800$ photon $\mathrm{MeV}^{-1}$. As shown in Fig. 2c, the light yield of $\left(\mathrm{C}_{38} \mathrm{H}_{34} \mathrm{P}_{2}\right) \mathrm{MnBr}_{4}$ is comparable to those of recently reported lead-free metal halides, such as $\mathrm{Cs}_{3} \mathrm{Cu}_{2} \mathrm{I}_{5}$ (79,279 photon $\left.\mathrm{MeV}^{-1}\right)^{43}$ and $\mathrm{Rb}_{2} \mathrm{CuBr}_{3}$ (91,056 photon $\left.\mathrm{MeV}^{-1}\right)^{33}$, and much better than those of $\mathrm{Rb}_{2} \mathrm{CuCl}_{3}(16,600$ photon $\left.\mathrm{MeV}^{-1}\right)^{34}$, widely investigated $\mathrm{CsPbBr}_{3}$ nanocrystals (21,000 photon $\left.\mathrm{MeV}^{-1}\right)^{22}$, and many commercially available scintillators, such as CsI:Tl (54,000 photon $\left.\mathrm{MeV}^{-1}\right)$ and $\mathrm{CdWO}_{4}$
(28,000 photon $\left.\mathrm{MeV}^{-1}\right)$. Moreover, based on the toxicity classification (health and environment) information of metal halides from material safety data sheet, $\left(\mathrm{C}_{38} \mathrm{H}_{34} \mathrm{P}_{2}\right) \mathrm{MnBr}_{4}$ is believed to be significantly less toxic than existing scintillators mentioned above. As shown in Supplementary Table 3, $\mathrm{Pb}(\mathrm{II}), \mathrm{Cu}(\mathrm{I})$, CsI, and $\mathrm{GdWO}_{4}$ possess the most severe toxicity in the environment, and $\mathrm{Tl}(\mathrm{I})$ and CsI are moderately toxic to health. Also, ${ }^{87} \mathrm{Rb}$ isotope is radioactive ${ }^{34}$. Mn(II) is considered to be less toxic for health and friendly to the environment. The stability of $\left(\mathrm{C}_{38} \mathrm{H}_{34} \mathrm{P}_{2}\right) \mathrm{MnBr}_{4}$ single crystals against $\mathrm{X}$-ray irradiation was evaluated by monitoring the changes of RL intensity under continuous X-ray irradiation with a dose rate of $89.4 \mu \mathrm{Gy} \mathrm{s}^{-1}$. Figure $2 \mathrm{~d}$ shows that little-to-no radio-degradation was observed after $4 \mathrm{~h}$ exposure to X-ray irradiation, suggesting high stability for scintillator applications.

X-ray imaging. To further validate the potential of $\left(\mathrm{C}_{38} \mathrm{H}_{34} \mathrm{P}_{2}\right)$ $\mathrm{MnBr}_{4}$ as scintillation material for practical X-ray imaging, a home-built X-ray imaging system was constructed, as shown in Supplementary Fig. 9. The scintillator screen was prepared by refilling the glass holder with $\left(\mathrm{C}_{38} \mathrm{H}_{34} \mathrm{P}_{2}\right) \mathrm{MnBr}_{4}$ fine powders with the particle size $<3 \mu \mathrm{m}$ (see scanning electron microscope (SEM) images in Supplementary Fig. 10). A speaker chip with a size of $9 \mathrm{~mm} \times 6 \mathrm{~mm}$, as shown in Fig. 2e, was used as a target placed between the X-ray source and the scintillator screen for 

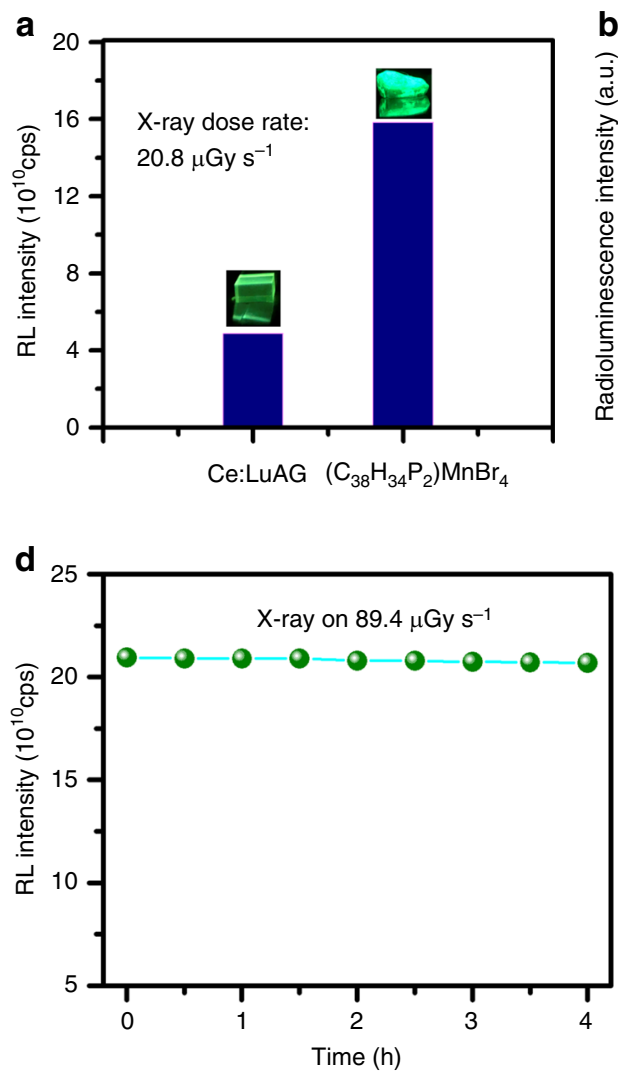
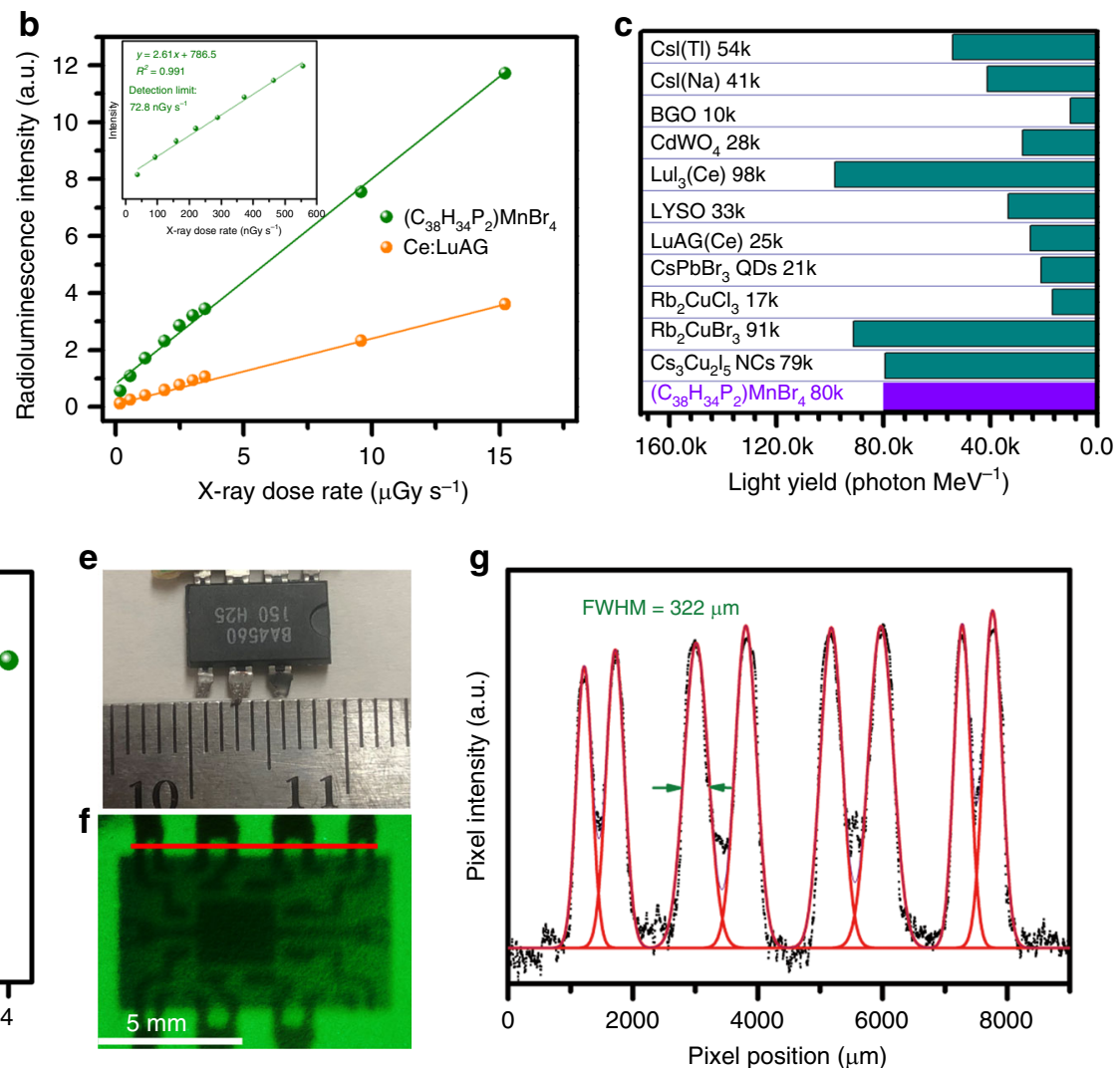

Fig. 2 X-ray scintillation properties of $\left(\mathbf{C}_{\mathbf{3 8}} \mathbf{H}_{\mathbf{3 4}} \mathbf{P}_{\mathbf{2}}\right) \mathbf{M n B r}_{\mathbf{4}}$. a Comparison of RL intensities for the standard reference Ce:LuAG and $\left(\mathrm{C}_{38} \mathrm{H}_{34} \mathrm{P}_{2}\right) \mathrm{MnBr}{ }_{4}$ under dose rate of $20.8 \mu \mathrm{Gy} \mathrm{s}^{-1}$. The inset shows the corresponding images under the same $\mathrm{X}$-ray irradiation. $\mathbf{b}$ Dose rate dependence of the RL intensity of standard reference Ce:LuAG and $\left(\mathrm{C}_{38} \mathrm{H}_{34} \mathrm{P}_{2}\right) \mathrm{MnBr}_{4}$. The inset shows the detection limit measurement under low $\mathrm{X}$-ray dose for $\left(\mathrm{C}_{38} \mathrm{H}_{34} \mathrm{P}_{2}\right) \mathrm{MnBr}_{4}$. The detection limit can be achieved when the RL intensity is three times higher than the background intensity. c Comparison of scintillator light yields of $\left(\mathrm{C}_{38} \mathrm{H}_{34} \mathrm{P}_{2}\right) \mathrm{MnBr}_{4}$ and previously reported and commercially available scintillators. $\mathbf{d}$ The change of the RL intensity under continuous $\mathrm{X}$-ray excitation with a dose rate of $89.4 \mu \mathrm{Gy} \mathrm{s}^{-1}$. e Image of a speaker chip under bright-field. $\mathbf{f}$ The X-ray images of the speaker chip by using $\left(\mathrm{C}_{38} \mathrm{H}_{34} \mathrm{P}_{2}\right) \mathrm{MnBr}_{4} \mathrm{scintillator}$ screen, acquired with a digital camera. $\mathbf{g}$ Spatial resolution measurement by the fitting of intensity spread profile with Gaussian function. The FWHM was taken as resolution. The red line in $\mathbf{f}$ shows the data trace of collection.

$\mathrm{X}$-ray image. The configuration inside of the chip cannot be seen directly with our eyes, which however could be revealed clearly by $\mathrm{X}$-ray imaging using a $\left(\mathrm{C}_{38} \mathrm{H}_{34} \mathrm{P}_{2}\right) \mathrm{MnBr}_{4}$-based scintillator (Fig. 2f). The large difference in X-ray absorption for different materials in the chip resulted in spatial intensity contrast displayed in the scintillator screen. The spatial resolution was calculated as $0.322 \mathrm{~mm}$ by fitting the point spread function of the intensity profile (Fig. $2 \mathrm{~g}$ ). Image contrast is another important parameter for practical imaging applications; image lag or ghosting would happen if the emission with a long lifetime has a strong afterglow after X-ray being turned off. To exclude the effect of afterglow, we measured the afterglow intensities of $\left(\mathrm{C}_{38} \mathrm{H}_{34} \mathrm{P}_{2}\right) \mathrm{MnBr}_{4}$, as shown in Supplementary Fig. 11. The intensity decreased to the background level in $10 \mathrm{~ms}$ after the cease of the excitation source, indicating the suitability for high contrast imaging. The excellent performance of X-ray imaging could be attributed to the negligible self-absorption, high PLQE, light yield, and low detection limit of $\left(\mathrm{C}_{38} \mathrm{H}_{34} \mathrm{P}_{2}\right) \mathrm{MnBr}_{4}{ }^{33,34,43,44}$.

Flexible devices have received tremendous attention nowadays for their good foldability, high crack resistance, favorable compatibility, and potential application in portable and wearable devices. Here, flexible scintillators with large size $\left(4.5 \times 5.8 \mathrm{~cm}^{2}\right)$ were demonstrated by blending $\left(\mathrm{C}_{38} \mathrm{H}_{34} \mathrm{P}_{2}\right) \mathrm{MnBr}_{4}$ fine powders with polydimethylsiloxane (PDMS). As shown in Fig. 3a-c, the resulting films show excellent flexibility, which can be easily bent and stretched. Moreover, the film shows high uniformity and strong emission under UV irradiation (Fig. 3d-f). The scintillation performance of flexible scintillation screens was characterized as shown in Supplementary Fig. 12, which exhibit excellent linearities to the $\mathrm{X}$-ray dose rates in a large range from $36.7 \mathrm{nGy} \mathrm{s}^{-1}$ to $89.4 \mu \mathrm{Gy} \mathrm{s}^{-1}$, with a slightly lower light yield (66,256 photon $\mathrm{MeV}^{-1}$ ) and detection limit (461.1 nGy s$\left.{ }^{-1}\right)$, as compared to those of single crystals. This is not surprising, considering that the content of $\left(\mathrm{C}_{38} \mathrm{H}_{34} \mathrm{P}_{2}\right) \mathrm{MnBr}_{4}$ is reduced in the blends, the distribution of $\left(\mathrm{C}_{38} \mathrm{H}_{34} \mathrm{P}_{2}\right) \mathrm{MnBr}_{4}$ might not be perfectly uniform in the blends, and PDMS could also affect the $\mathrm{X}$-ray absorption. To demonstrate the capability of the X-ray imaging, a wrench and a speaker chip were scanned as the targets (Fig. 3g, h). Distinct color contrast and detail inside of the chip can be displayed in the flexible film with good resolution.

\section{Discussion}

In conclusion, a new 0D organic manganese (II) halide hybrid $\left(\mathrm{C}_{38} \mathrm{H}_{34} \mathrm{P}_{2}\right) \mathrm{MnBr}_{4}$ has been developed to exhibit highly efficient green emission upon photo and X-ray excitations. Single crystals with sizes of $>1$ in. could be prepared via a facile solution growth method at room temperature, which shows remarkable scintillation properties with excellent response linearity to dose rate, high light yield, and low detection limits. The X-ray scintillation characteristics were found to be superior to those of metal halide perovskite nanocrystals and most of today's commercially available scintillators. X-ray imaging was also successfully demonstrated with high resolution. The low-cost, 

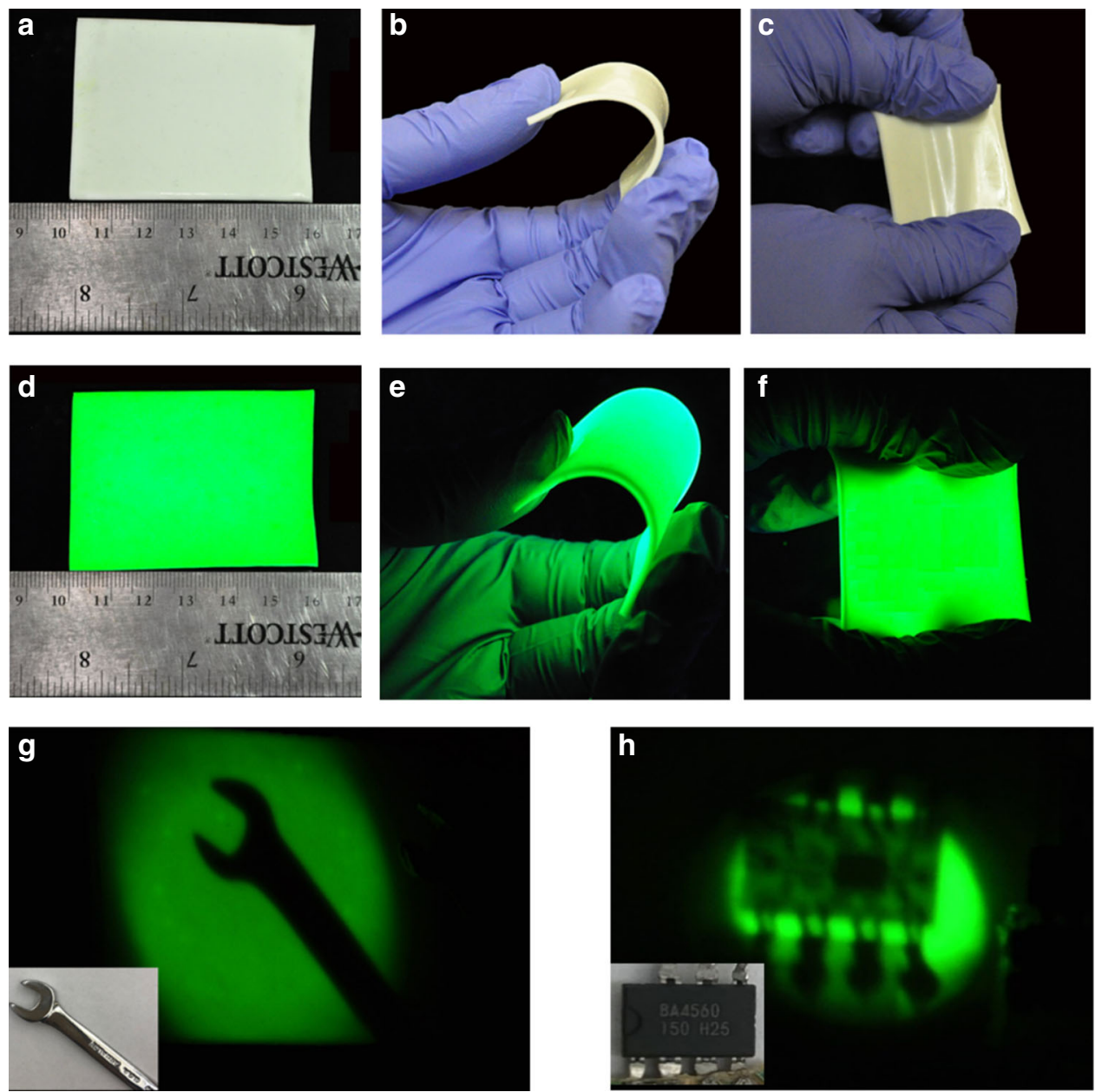

Fig. 3 Flexible X-ray scintillator screens. The photographs of a flexible scintillator screen based on $\left(\mathrm{C}_{38} \mathrm{H}_{34} \mathrm{P}_{2}\right) \mathrm{MnBr}_{4}$ a under flatting, $\mathbf{b}$ under bending stress, c under stretching, under ambient light. The photographs of a flexible scintillator screen based on $\left(\mathrm{C}_{38} \mathrm{H}_{34} \mathrm{P}_{2}\right) \mathrm{MnBr}_{4}$ under UV excitation d under flatting, e under bending stress, $\mathbf{f}$ under stretching. $\mathbf{g}$ X-ray image of a wrench by using a flexible $\left(\mathrm{C}_{38} \mathrm{H}_{34} \mathrm{P}_{2}\right) \mathrm{MnBr}_{4}$ scintillator screen, inset shows the wrench used for scanning. $\mathbf{h}$ X-ray image of a speaker chip by using a flexible $\left(\mathrm{C}_{38} \mathrm{H}_{34} \mathrm{P}_{2}\right) \mathrm{MnBr}_{4}$ scintillator screen, inset shows the speaker chip used for scanning.

facile preparation, environmentally friendly, and state-of-theart scintillation performance make this organic manganese (II) hybrid $\left(\mathrm{C}_{38} \mathrm{H}_{34} \mathrm{P}_{2}\right) \mathrm{MnBr}_{4}$ a highly promising scintillator for commercial applications. Our work paves a new way to explore new low-cost, high-performance eco-friendly hybrid materials for radiation scintillators.

\section{Methods}

Materials. Manganese (II) bromide, and ethylenebis(triphenylphosphonium bromide) were purchased from Sigma-Aldrich. Dimethylformamide (99.8\%), DCM (99.9\%), and diethyl ether $\left(\mathrm{Et}_{2} \mathrm{O}, 99.8 \%\right)$ was purchased from VWR. Standard scintillator Ce:LuAG was purchased from Jiaxing AOSITE Photonics Technology Co., Ltd. All reagents and solvents were used without further purification unless otherwise stated.

Growth of OD $\left(\mathbf{C}_{\mathbf{3} 8} \mathbf{H}_{\mathbf{3}} \mathbf{P}_{\mathbf{2}}\right) \mathbf{M n B r}_{\mathbf{4}}$ single crystals. $\mathrm{MnBr}_{2}(429.5 \mathrm{mg}, 2.0 \mathrm{mmol})$ and ethylenebis(triphenylphosphonium bromide) $(1.424 \mathrm{~g}, 2.0 \mathrm{mmol}$ ) were dissolved in $10 \mathrm{~mL}$ DCM solution and then filtered into a $20 \mathrm{~mL}$ vial to form a clear precursor solution. Then, the vial was placed in a $100 \mathrm{~mL}$ vial with $60 \mathrm{~mL} \mathrm{Et}_{2} \mathrm{O}$ inside. The as-prepared solution was sealed and left to stand for $\sim 3$ days to afford pale green block crystals. Yield $\sim 89 \%$.

Scintillator screen. First, $\left(\mathrm{C}_{38} \mathrm{H}_{34} \mathrm{P}_{2}\right) \mathrm{MnBr}_{4}$ single crystals were hand-ground to fine powders by using mortar and pestle. Then, the scintillator screen was prepared by filling the fine powder into the PXRD holder. The flexible screen was prepared by blending the powder with a two-part PDMS EI-1184 at a mass ratio of $40 \%$. The mixture gel was placed in a polytetrafluoroethylene mold and cured at $100^{\circ} \mathrm{C}$ for $30 \mathrm{~min}$ in a muffle furnace and then the flat and smooth film was formed after cooling down the mixture gel to room temperature.
Single-crystal X-ray diffraction. Single-crystal X-ray data for the $\left(\mathrm{C}_{38} \mathrm{H}_{34} \mathrm{P}_{2}\right)$ $\mathrm{MnBr}_{4}$ hybrid were collected using a Rigaku XtaLAB Synergy-S diffractometer equipped with a HyPix-6000HE Hybrid Photon Counting (HPC) detector and dual $\mathrm{Mo}$ and $\mathrm{Cu}$ microfocus sealed X-ray source.

Powder X-ray diffraction. The PXRD analysis was performed on Panalytical X'PERT Pro Powder X-Ray Diffractometer using Copper X-ray tube (standard) radiation at a voltage of $40 \mathrm{kV}$ and $40 \mathrm{~mA}$, and X'Celerator RTMS detector. The diffraction pattern $S$ was scanned over the angular range of $5-40^{\circ}(2 \theta)$ with a step size of 0.02 , at room temperature.

Absorption spectrum measurements. Absorption spectra of $\left(\mathrm{C}_{38} \mathrm{H}_{34} \mathrm{P}_{2}\right) \mathrm{MnBr}_{4}$ hybrid were measured at room temperature on Cary 5000 UV-Vis-NIR spectrophotometer.

PL steady-state studies. Steady-state PL spectrum of $\left(\mathrm{C}_{38} \mathrm{H}_{34} \mathrm{P}_{2}\right) \mathrm{MnBr}_{4}$ was obtained at room temperature on an FS5 spectrofluorometer (Edinburgh Instruments).

Photoluminescence quantum efficiency. The PLQEs were acquired using a Hamamatsu Quantaurus-QY Spectrometer (Model C11347-11) equipped with a xenon lamp, integrated sphere sample chamber, and CCD detector. The PLQEs were calculated by the equation: $\eta_{\mathrm{QE}}=\mathrm{I}_{S} /\left(\mathrm{E}_{\mathrm{R}}-\mathrm{E}_{\mathrm{S}}\right)$, in which $\mathrm{I}_{\mathrm{S}}$ represents the luminescence emission spectrum of the sample, $\mathrm{E}_{\mathrm{R}}$ is the spectrum of the excitation light from the empty integrated sphere (without the sample), and $E_{S}$ is the excitation spectrum for exciting the sample.

Time-resolved PL. Time-resolved emission data were collected at room temperature using the Edinburgh FLS920 fluorescence spectrometer. The dynamics of 
emission decay were monitored by using the time-correlated single-photon counting capability with data collection for 10,000 counts. The average lifetime was obtained by the single-exponential fitting.

Afterglow intensity measurement. The afterglow intensity was recorded by continuously irradiating $20 \mathrm{~s}$ under xenon lamp and then the afterglow signal was collected by Hamamatsu R928 PMT with the time interval of $10 \mathrm{~ms}$.

\section{Thermogravimetric analysis and differential scanning calorimetry. TGA and} DSC were carried out using a TA instruments Q600 system. The samples were heated from room temperature to $700^{\circ} \mathrm{C}$ at a rate of $5^{\circ} \mathrm{C} \mathrm{min}^{-1}$, under a nitrogen flux of $100 \mathrm{~mL} \mathrm{~min}^{-1}$.

$\mathbf{R L}$ and X-ray imaging. The RL spectra were acquired by using an Edinburgh FS5 spectrofluorometer (Edinburgh Instruments) equipped with an X-ray source (Amptek Mini-X tube with an Au target and $4 \mathrm{~W}$ maximum power output). The $\mathrm{X}$ ray response intensity was examined and collected by a Hamamatsu R928 PMT The scintillator light yield was estimated using the following equation. Here, the Ce:LuAG was used as the reference with a known light yield of 25,000 photon $\mathrm{MeV}^{-1}$. The spectrum of $\left(\mathrm{C}_{38} \mathrm{H}_{34} \mathrm{P}_{2}\right) \mathrm{MnBr}_{4}$ is similar to that of Ce:LuAG after correcting the intensity and wavelength from the correction files of R928 PMT. Then, the light yield could be estimated by comparing the corrected response amplitude $(R)$ of the two samples using Eq. (1):

$\frac{\mathrm{LY}_{\mathrm{C}_{38} \mathrm{H}_{34} \mathrm{P}_{2} \mathrm{MnBr}_{4}}}{\mathrm{LY}_{\mathrm{Ce}: \mathrm{LuAG}}}=\frac{\mathrm{R}_{\mathrm{C}_{38} \mathrm{H}_{34} \mathrm{P}_{2} \mathrm{MnBr}_{4}}}{\mathrm{R}_{\mathrm{Ce}: \mathrm{LuAG}}} \times \frac{\int \mathrm{I}_{\mathrm{Ce}: \mathrm{LuAG}}(\lambda) \mathrm{S}(\lambda) \mathrm{d} \lambda / \int \mathrm{I}_{\mathrm{Ce}: \mathrm{LuAG}}(\lambda) \mathrm{d} \lambda}{\int \mathrm{I}_{\mathrm{C}_{38} \mathrm{H}_{34} \mathrm{P}_{2} \mathrm{MnBr}_{4}}(\lambda) \mathrm{S}(\lambda) \mathrm{d} \lambda / \int \mathrm{I}_{\mathrm{C}_{38} \mathrm{H}_{34} \mathrm{P}_{2} \mathrm{MnBr}_{4}}(\lambda) \mathrm{d} \lambda}$.

The radiation dose rate of the $\mathrm{X}$-ray source was calibrated by using an ion chamber dosimeter. The X-ray images were acquired by using a digital camera (Nikon D90).

Scanning electron microscopy. The particle size of $\left(\mathrm{C}_{38} \mathrm{H}_{34} \mathrm{P}_{2}\right) \mathrm{MnBr}_{4}$ fine powders were investigated by FEI Nova NanoSEM 400 SEM.

\section{Data availability}

The data that support the findings of this study are available from the corresponding author on reasonable request. The X-ray crystallographic data for this paper has been deposited at the Cambridge Crystallographic Data Centre (CCDC), under deposition number 1972108. These data can be obtained free of charge from the CCDC via www. ccdc.cam.ac.uk/data_request/cif.

Received: 25 February 2020; Accepted: 6 August 2020;

Published online: 28 August 2020

\section{References}

1. Zhuravleva, M., Friedrich, S. \& Melcher, C. L. Praseodymium valence determination in $\mathrm{Lu}_{2} \mathrm{SiO}_{5}, \mathrm{Y}_{2} \mathrm{SiO}_{5}$, and $\mathrm{Lu}_{3} \mathrm{Al}_{5} \mathrm{O}_{12}$ scintillators by $\mathrm{x}$-ray absorption spectroscopy. Appl. Phys. Lett. 101, 101902 (2012).

2. Weber, M. J. Inorganic scintillators: today and tomorrow. J. Lumin. 100, 35-45 (2002)

3. Lecoq, P. Development of new scintillators for medical applications. Nucl Instrum. Meth. A 809, 130-139 (2016).

4. Kramer, K. W., Dorenbos, P., Gudel, H. U. \& van Eijk, C. W. E. Development and characterization of highly efficient new cerium doped rare earth halide scintillator materials. J. Mater. Chem. 16, 2773-2780 (2006).

5. Liu, S. P. et al. Effect of $\mathrm{Mg}^{2+}$ co-doping on the scintillation performance of LuAG: Ce ceramics. Phys. Stat. Sol. R 8, 105-109 (2014).

6. Nikl, M. \& Yoshikawa, A. Recent R\&D trends in inorganic single-crystal scintillator materials for radiation detection. Adv. Opt. Mater. 3, 463-481 (2015).

7. Moser, S. W., Harder, W. F., Hurlbut, C. R. \& Kusner, M. R. Principles and practice of plastic scintillator design. Radiat. Phys. Chem. 41, 31-36 (1993).

8. Schuster, P. \& Brubaker, E. Investigating the anisotropic scintillation response in anthracene through neutron, gamma-ray, and muon measurements. IEEE Trans. Nucl. Sci. 63, 1942-1954 (2016).

9. Ariesanti, E., Hawrami, R., Burger, A. \& Motakef, S. Improved growth and scintillation properties of intrinsic, non-hygroscopic scintillator $\mathrm{Cs}_{2} \mathrm{HfCl}_{6}$. J. Lumin. 217, 116784 (2020).

10. Kim, Y. C. et al. Printable organometallic perovskite enables large-area, lowdose X-ray imaging. Nature 550, 87-91 (2017).

11. Yakunin, S. et al. Detection of X-ray photons by solution-processed lead halide perovskites. Nat. Photonics 9, 444-449 (2015).
12. Wei, H. T. et al. Sensitive X-ray detectors made of methylammonium lead tribromide perovskite single crystals. Nat. Photonics 10, 333-339 (2016).

13. Wei, W. et al. Monolithic integration of hybrid perovskite single crystals with heterogenous substrate for highly sensitive X-ray imaging. Nat. Photonics 11, 315-321 (2017).

14. Shrestha, S. et al. High-performance direct conversion X-ray detectors based on sintered hybrid lead triiodide perovskite wafers. Nat. Photonics 11, 436-440 (2017).

15. Wei, H. T. \& Huang, J. S. Halide lead perovskites for ionizing radiation detection. Nat. Commun. 10, 1066 (2019).

16. Birowosuto, M. D. et al. X-ray scintillation in lead halide perovskite crystals. Sci. Rep. 6, 37254 (2016).

17. Stoumpos, C. C. et al. Crystal growth of the perovskite semiconductor $\mathrm{Cs} \mathrm{PbBr}_{3}$ : A new material for high-energy radiation detection. Cryst. Growth Des. 13, 2722-2727 (2013).

18. Heiss, W. \& Brabec, C. X-ray imaging: perovskites target X-ray detection. Nat. Photonics 10, 288-289 (2016).

19. Liu, J. Y. et al. Flexible, printable soft-X-ray detectors based on all-inorganic perovskite quantum dots. Adv. Mater. 31, 1901644 (2019).

20. Pan, W. C. et al. Hot-pressed $\mathrm{CsPbBr}_{3}$ quasi-monocrystalline film for sensitive direct X-ray detection. Adv. Mater. 31, 1904405 (2019).

21. Chen, Q. S. et al. All-inorganic perovskite nanocrystal scintillators. Nature 561, 88-93 (2018).

22. Zhang, Y. H. et al. Metal halide perovskite nanosheet for X-ray highresolution scintillation imaging screens. ACS Nano 13, 2520-2525 (2019).

23. Heo, J. H. et al. High-performance next-generation perovskite nanocrystal scintillator for nondestructive X-ray imaging. Adv. Mater. 30, 1801743 (2018)

24. Wang, L. L. et al. Ultra-stable $\mathrm{CsPbBr}_{3}$ perovskite nanosheets for X-ray imaging screen. Nano-Micro Lett. 11, 52 (2019).

25. Mykhaylyk, V. B., Kraus, H. \& Saliba, M. Bright and fast scintillation of organolead perovskite $\mathrm{MAPbBr}_{3}$ at low temperatures. Mater. Horiz. 6, 1740-1747 (2019)

26. Cao, F. et al. Shining emitter in stable host: design halide perovskite scintillators for X-ray imaging from commercial concept. ACS nano 14, 5183-5193 (2019).

27. Zhou, C. K. et al. Low dimensional metal halide perovskites and hybrids. Mater. Sci. Eng. R 137, 38-65 (2019).

28. Zhou, C. K. et al. Luminescent zero-dimensional organic metal halide hybrids with near-unity quantum efficiency. Chem. Sci. 9, 586-593 (2018)

29. Zhou, C. K. et al. Low-dimensional organic tin bromide perovskites and their photoinduced structural transformation. Angew. Chem. Int. Ed. 56, 9018-9022 (2017).

30. Zhou, C. K. et al. Facile preparation of light emitting organic metal halide crystals with near-unity quantum efficiency. Chem. Mater. 30, 2374-2378 (2018).

31. Pan, W. C. et al. $\mathrm{Cs}_{2} \mathrm{AgBiBr}_{6}$ single-crystal $\mathrm{X}$-ray detectors with a low detection limit. Nat. Photonics 11, 726-732 (2017).

32. Morad, V. et al. Disphenoidal zero-dimensional lead, tin, and germanium halides: Highly emissive singlet and triplet self-trapped excitons and X-ray scintillation. J. Am. Chem. Soc. 141, 9764-9768 (2019).

33. Yang, B. et al. Lead-free halide $\mathrm{Rb}_{2} \mathrm{CuBr}_{3}$ as sensitive $\mathrm{X}$-ray scintillator. $A d v$. Mater. 31, 1904711 (2019).

34. Zhao, X. et al. All-inorganic copper halide as a stable and self-absorption-free X-ray scintillator. J. Phys. Chem. Lett. 11, 1873-1880 (2020).

35. Xu, L. J., Sun, C. Z., Xiao, H., Wu, Y. \& Chen, Z. N. Green-light-emitting diodes based on tetrabromide manganese(II) complex through solution process. Adv. Mater. 29, 1605739 (2017).

36. $\mathrm{Li}, \mathrm{M}$. Z. et al. Lead-free hybrid metal halides with a green-emissive $\left[\mathrm{MnBr}_{4}\right]$ unit as a selective turn-on fluorescent sensor for acetone. Inorg. Chem. $\mathbf{5 8}$ 13464-13470 (2019).

37. Morad, V. et al. Manganese(II) in tetrahedral halide environment: factors governing bright green luminescence. Chem. Mater. 31, 10161-10169 (2019).

38. Wu, Y., Zhang, X., Xu, L. J., Yang, M. \& Chen, Z. N. Luminescent vapochromism due to a change of the ligand field in a one-dimensional manganese(II) coordination polymer. Inorg. Chem. 57, 9175-9181 (2018)

39. Ye, H. Y. et al. High-temperature ferroelectricity and photoluminescence in a hybrid organic-inorganic compound: (3-Pyrrolinium) $\mathrm{MnCl}_{3}$. J. Am. Chem. Soc. 137, 13148-13154 (2015).

40. Zhang, Y. et al. Highly dfficient red-light emission in an organic-inorganic hybrid ferroelectric: (Pyrrolidinium) $\mathrm{MnCl}_{3}$. J. Am. Chem. Soc. 137, 4928-4931 (2015).

41. Su, B. B., Molokeev, M. S. \& Xia, Z. G. $\mathrm{Mn}^{2+}$-based narrow-band greenemitting $\mathrm{Cs}_{3} \mathrm{MnBr}_{5}$ phosphor and the performance optimization by $\mathrm{Zn}^{2+}$ alloying. J. Mater. Chem. C 7, 11220-11226 (2019).

42. Qin, Y. Y. et al. Designing highly efficient phosphorescent neutral tetrahedra manganese(II) complexes for organic light-emitting diodes. Adv. Opt. Mater. 7, 1801160 (2019). 
43. Lian, L. et al. Efficient and reabsorption-free radioluminescence in $\mathrm{Cs}_{3} \mathrm{Cu}_{2} \mathrm{I}_{5}$ nanocrystals with self-trapped excitons. Adv. Sci. 7, 2000195 (2020).

44. He, Q. et al. Highly stable organic antimony halide crystals for X-ray scintillation. ACS Mater. Lett. 2, 633-638 (2020).

\section{Acknowledgements}

This work was primarily supported by the Air Force Office of Scientific Research, under the Organic Materials Chemistry program contract no. FA9550-18-1-0231. Partial of the work on the characterization of X-ray scintillation properties was supported by the National Science Foundation (DMR-1709116) and the Florida State University Office of Research. This work made use of the Rigaku Synergy-S single-crystal X-ray diffractometer, which was acquired through the National Science Foundation MRI program (CHE-1828362). M.W. thanks the support from the National Science Foundation (ECCS-1912911). We thank Dr. Yang Zhang for the help with X-ray images, Dr. J.S. Raaj Vellore Winfred for the TGA and DSC measurements, and Dr. Yuhai Zhang for the spatial resolution measurement.

\section{Author contributions}

L.-J.X. and B.M. conceived the experiments and analyzed and interpreted the data. L.-J.X. carried out sample preparation and characterization, and scintillation measurements. Q.H., M.W., and L.-J.X. developed the mini-X-ray setup. X.L. did the calibration of X-ray dose rate. L.-J.X. and B.M. wrote the manuscript. The project was planned, directed, and supervised by B.M. All the authors discussed the results and commented on the manuscript.

\section{Competing interests}

L.-J.X, Q.H., and B.M. have filed a patent application entitled "X-Ray Scintillators and Methods" in the United States Patent and Trademark Office on March 13, 2020, under U.S. Application Serial No. 62/989,015.

\section{Additional information}

Supplementary information is available for this paper at https://doi.org/10.1038/s41467020-18119-y.

Correspondence and requests for materials should be addressed to B.M.

Peer review information Nature Communication thanks Gerwin Gelinck and Jinsong Huang for their contributions to the peer review of this work. Peer review reports are available.

Reprints and permission information is available at http://www.nature.com/reprints

Publisher's note Springer Nature remains neutral with regard to jurisdictional claims in published maps and institutional affiliations.

\section{(c) (i)}

Open Access This article is licensed under a Creative Commons Attribution 4.0 International License, which permits use, sharing, adaptation, distribution and reproduction in any medium or format, as long as you give appropriate credit to the original author(s) and the source, provide a link to the Creative Commons license, and indicate if changes were made. The images or other third party material in this article are included in the article's Creative Commons license, unless indicated otherwise in a credit line to the material. If material is not included in the article's Creative Commons license and your intended use is not permitted by statutory regulation or exceeds the permitted use, you will need to obtain permission directly from the copyright holder. To view a copy of this license, visit http://creativecommons.org/ licenses/by/4.0/.

(C) The Author(s) 2020 